\title{
Prediction of advanced colonic neoplasm in symptomatic patients: a scoring system to prioritize colonoscopy (COLONOFIT study)
}

Fernando Fernández-Bañares ${ }^{1,2^{*}}$ (D, Ramon Clèries ${ }^{3}$, Jaume Boadas ${ }^{4}$, Josepa Ribes $^{3}$, Joan Carles Oliva ${ }^{3}$, Antoni Alsius ${ }^{5}$, Xavier Sanz ${ }^{3}$, Eva Martínez-Bauer ${ }^{6}$, Sara Galter ${ }^{4}$, Mar Pujals ${ }^{1}$, Marta Pujol ${ }^{6}$, Patricia del Pozo ${ }^{4}$ and Rafel Campo ${ }^{6}$

\begin{abstract}
Background: Fast-track colonoscopy to detect patients with colorectal cancer based on high-risk symptoms is associated with low sensitivity and specificity. The aim was to derive a predictive score of advanced colonic neoplasia in symptomatic patients in fast-track programs.

Methods: All patients referred for fast-track colonoscopy were evaluated. Faecal immunological haemoglobin test (3 samples; positive $>4 \mu \mathrm{g} \mathrm{Hb} / \mathrm{g}$ ), and a survey to register clinical variables of interest were performed. Colorectal cancer and advanced adenoma were considered as advanced colonic neoplasia. A sample size of 600 and 500 individuals were calculated for each phase 1 and phase 2 of the study, respectively (Phase 1, derivation and Phase 2, validation cohort). A Bayesian logistic regression analysis was used to derive a predictive score.

Results: 1495 patients were included. Age (OR, 21), maximum faecal-Hb value (OR, 2.3), and number of positive samples $(O R, 28)$ presented the highest ORs predictive of advanced colonic neoplasia. The additional significant predictive variables adjusted for age and faecal-Hb variables in Phase 1 were previous colonoscopy (last 5 years) and smoking (no, ex/active). With these variables a predictive score of advanced colonic neoplasia was derived. Applied to Phase 2, patients with a Score $>20$ had an advanced colonic neoplasia probability of 66\% (colorectal cancer, $32 \%$ ), while those with a Score $\leq 10$, a probability of $10 \%$ (colorectal cancer, $1 \%$ ). Prioritizing patients with Score $>10,49.4 \%$ of patients would be referred for fast-track colonoscopy, diagnosing $98.3 \%$ of colorectal cancers and $77 \%$ of advanced adenomas.
\end{abstract}

Conclusions: A scoring system was derived and validated to prioritize fast-track colonoscopies according to risk, which was efficient, simple, and robust.

Keywords: Colorectal cancer, Advanced adenoma, Faecal immunological occult haemoglobin test, Fast-track colonoscopy

\section{Background}

Colorectal cancer (CRC) is the third most common malignancy in men and the second most common in women, and the fourth leading cause of cancer-related deaths worldwide [1]. Despite progress made in recent years in the diagnosis and treatment of this disease, a significant

\footnotetext{
* Correspondence: ffbanares@mutuaterrassa.es

'Department of Gastroenterology, Hospital Universitari Mutua Terrassa, Plaza Dr Robert 5, 08221 Terrassa, Barcelona, Spain

${ }^{2}$ Centro de Investigación Biomédica en Red de enfermedades hepáticas y digestivas (CIBERehd), Instituto Salud Carlos III, Madrid, Spain

Full list of author information is available at the end of the article
}

improvement in survival at 5 years has not been shown, which persists around $50 \%$. This is because over $80 \%$ of new cases are symptomatic patients, and the disease is advanced at the time of diagnosis. A significant percentage of CRC patients are diagnosed based on the presence of clinical symptoms associated with this malignancy [2-5]. It is therefore important to identify patients who have symptoms and/or signs of suspicion, so an early colonoscopy can be indicated. Recently, the proposed rule of 2week wait (2WW) referral system for the NHS (UK) has been re-evaluated [6]. This system was proposed in 2000

(c) The Author(s). 2019 Open Access This article is distributed under the terms of the Creative Commons Attribution 4.0 International License (http://creativecommons.org/licenses/by/4.0/), which permits unrestricted use, distribution, and reproduction in any medium, provided you give appropriate credit to the original author(s) and the source, provide a link to the Creative Commons license, and indicate if changes were made. The Creative Commons Public Domain Dedication waiver (http://creativecommons.org/publicdomain/zero/1.0/) applies to the data made available in this article, unless otherwise stated. 
to ensure that specialists in reference hospitals assess all patients with suspected CRC within 14 days after urgent referral by a primary care physician. This approach is based on the guidelines of the National Institute for Health and Care Excellence (NICE) criteria for suspected cancer [7]. However, different studies have shown the low sensitivity and specificity of the NICE criteria to refer for a $2 \mathrm{WW}$ program [8-11]. Although $77 \%$ of patients with $\mathrm{CRC}$ are referred by primary care physicians via urgent pathways, this system did not improve 5-year colorectal cancer survival [12]. This finding may be due to the fact that the symptoms when present very often indicate an advanced disease, and once a cancer became symptomatic, early treatment did not improve survival. Besides, the $2 \mathrm{WW}$ rule has been criticized, because of the low overall cancer detection rate, due to the poor specificity of the patient clinical symptoms (common with benign bowel diseases), resulting in overwhelming referral rates. The new NICE guidelines (July 2017) suggest using faecal occult blood test for clinical symptoms associated with a low probability of having CRC (PPV $<3 \%)$.

In this scenario, a number of CRC prediction models have been designed and validated in different settings [13]. These prediction models are calculated from mathematical equations based mainly on symptoms [14-16], and recently also on 1-sample faecal immunological test (FIT) $[11,17]$. The patients included in those studies were symptomatic, but they did not always fulfil the criteria for a fast-track program. The diagnostic accuracy of these risk-scoring models is generally considered satisfactory and better than the existing referral criteria, but at present, they have not been widely recommended, perhaps as a consequence of the complicated mathematical equations required for their calculation.

In spite that a meta-analysis showed that in averagerisk asymptomatic patients increasing the number of FIT samples did not affect the pooled performance characteristics of FITs for CRC [18], recent studies suggested that in symptomatic patients using either 2 or 3 tests provided the best discrimination for CRC [19-23].

Thus, the aim of the study was to derive and validate a predictive risk score to determine the pre-test-probability of advanced colonic neoplasia (ACN) in symptomatic patients with indication of a fast-track colonoscopy. In addition, to assess the accuracy for ACN diagnosis of a 3sample FIT as compared to 1-sample FIT.

\section{Methods}

The study protocol is available as a supplementary file (Additional file 1).

\section{Study population}

All patients in the fast-track colonoscopy programs for CRC in the three participating hospitals were included in the period March-2014 to September-2016. Healthcare areas of these hospitals comprise a population of about 917,905 inhabitants. Patients with high-risk symptoms for CRC were sent for a full colonoscopy following the government's program to expedite the diagnosis of CRC. All the colonoscopies in the health areas involved are performed at the endoscopic units of the three centres. Each unit performed more than 3,000 colonoscopies a year. Fast-track colonoscopy was requested mainly from primary care physicians or gastroenterology specialists in primary care medicine, but also from the hospital outpatient visits (different medical and surgical specialties). Inclusion criteria were as follows: 1. Age of 18 years or more; 2. Fulfilment of the criteria for a fasttrack colonoscopy based on NICE guidelines [7]; 3. Signing informed consent. The exclusion criteria included pregnancy, asymptomatic individuals who were undergoing colonoscopy for CRC screening, patients with a previous history of colonic disease scheduled for a surveillance colonoscopy, patients requiring hospital admission, and patients whose symptoms had ceased within the three months before evaluation.

The clinical research ethics committees of the three centres approved the study and patients provided written informed consent.

\section{Interventions}

Trained case managers (specialized nurses) conducted the patients' personal interviews to assure a standardized and proper collection of faecal samples, the fulfilment of the inclusion and exclusion criteria, and the signing of informed consent. In all patients the following interventions were performed: 1 . FIT on three different days in the week prior to colonoscopy; and 2. A patient consultation questionnaire including a detailed assessment of colorectal symptoms, personal and family history of polyps/CRC, smoking and consumption of medication increasing the risk of a gastrointestinal haemorrhage (NSAIDs, aspirin, anticoagulants). In the case of rectal bleeding, patients were instructed, if possible, to collect faecal samples on days that they did not have rectal bleeding. Faecal haemoglobin was analysed using iFOB kit (Linear Chemicals SL, Barcelona, Spain) (see detailed description of the test in Additional file 2) which is able to detect values of $4 \mu \mathrm{g} \mathrm{Hb} / \mathrm{g}$ faeces. Quantitative values were recorded for each of the three samples from 4 to higher than $160 \mu \mathrm{g} \mathrm{Hb} / \mathrm{g}$ faeces.

A full colonoscopy with iv sedation with colon biopsies and/or polypectomy, if necessary, was performed on all evaluated patients. Endoscopists involved in the study had more than 2 years of experience from routine clinical colonoscopies, undertaking at least 200 procedures per year, with caecal intubation rates over $97 \%$. The cleaning degree (Boston scale), results of the exploration, and pathology 
studies were registered. Colonoscopies with insufficient preparation (Boston scale $=1$ or less in one colonic segment) were repeated. In the case of multiple polyps, the number of polyps, the size of the largest, and the most advanced pathology were registered. If CRC was recognized, its stage (TNM classification) and location (right, transverse, or left colon) was recorded.

\section{Main outcome}

The main outcome was ACN detection, which was defined as the presence of CRC or advanced adenoma (AA) ( $>1 \mathrm{~cm}$ or high-grade dysplasia or villous component). Intramucosal carcinoma (Tis) was considered as AA.

\section{Derivation and validation cohort}

The rule of thumb of 10 events per variable was used to obtain a derivation cohort, assuming that the logistic regression model may account for between 10 and 15 dummy predictor variables [24]. In this line, assuming a prevalence of $\mathrm{ACN}$ of $20 \%$ ( $8 \%$ CRC, $12 \%$ AA) [25], a minimum sample size cohort of 600 individuals was required (expected events of 120). During the timeline of the study (March-2014 to May-2015) we could derive a larger cohort of $N=761$ individuals in order to guarantee the number of dummy variables. From these individuals FIT was not available in 30 out of them, leading to a final cohort of $N=731$ individuals.

We settled that a minimum sample size of 500 was required for the validation phase (see Additional file 3). Finally, we recruited a cohort of 527 individuals. In addition, symptomatic patients with no indication for a fast-track colonoscopy and negative FIT were included, to have enough patients with negative FIT in the lowrisk group (finally, 136 in phase 1 and 101 in phase 2). This totals 867 individuals in phase $1(731+136)$ with
171 events (104 advanced adenomas and 67 colorectal cancers), and 628 individuals in phase $2(527+101)$ with 148 events (99 AA and 49 CRC) (Fig. 1).

\section{Derivation of the FIT variables included in the model}

Three samples for FIT were obtained in each of the $N=$ 867 individuals and we used the maximum $\mathrm{f}-\mathrm{Hb}$ value (MAXFIT) out of the three samples in each individual. Since the variable $\mathrm{f}-\mathrm{Hb}$ did not follow a Normal distribution even after logarithmic transformation, as has been reported elsewhere [17], and the risk of CRC did not have a linear relationship to $\mathrm{f}-\mathrm{Hb}$, MAXFIT was introduced as a categorical variable. We selected as cut-off $11 \mu \mathrm{g} \mathrm{Hb} / \mathrm{g}$ faeces (see Additional file 3). Therefore, we assumed three categories for the MAXFIT variable: $\leq 4$, $>4$ to $11,>11 \mu \mathrm{g} \mathrm{Hb} / \mathrm{g}$ faeces. In addition, since we collected three faecal samples, we also used a variable which counts the number of samples with FIT $>4 \mu \mathrm{g} \mathrm{Hb} /$ $\mathrm{g}$ faeces (NSAMPLES $>4$ ). This variable could take values in the range from 0 to 3 and was introduced in the model as an interaction term with MAXFIT variable.

\section{Development of the risk score}

Univariate analysis was carried out on the derivation set using the Pearson chi-square method to examine the association between clinical risk factors and advanced neoplasia. In our study, age and MAXFIT were the variables associated with higher ORs in the univariate analyses (see Tables 1 and 2), and it is in accordance with results reported in previous studies [17]. Unlike other studies, we have also considered the number of positive samples, since this variable improved the predictive performance of the model. Thus, the prognostic variables included in the seminal multivariate logistic model were Age, MAXFIT and NSAMPLES $>4$. Then, significant variables in the

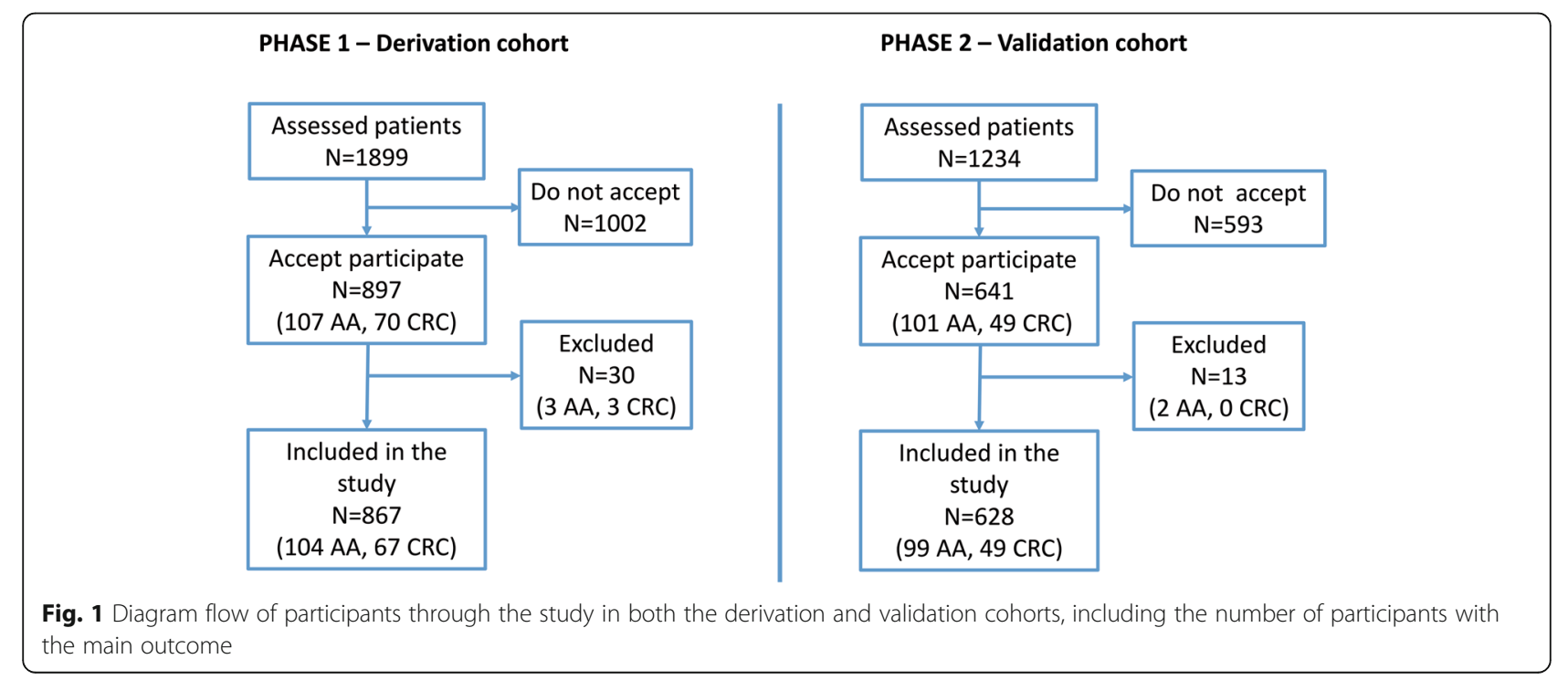


Table 1 Crude and adjusted ORs of age and FIT variables for association with ACN in the derivation (Phase I) cohort (Seminal model: C-Statistic $=0.846$; Brier Score $=0.115$; Hosmer-Lemeshow $p$-value $=0.796$ )

\begin{tabular}{|c|c|c|c|c|}
\hline$x$ & Control group (non-AA, non-CRC) & $A A+C R C$ & OR (Crude) & OR (Adjusted) \\
\hline \multicolumn{5}{|c|}{ Age group (years) } \\
\hline$\leq 40$ & $66(9.48 \%)$ & $1(0.58 \%)$ & Ref. & Ref. \\
\hline $40-50$ & $98(14.1 \%)$ & $6(3.51 \%)$ & $3.61[0.58 ; 94.9]$ & $4.62[0.49 ; 43.6]$ \\
\hline $50-60$ & $157(22.6 \%)$ & 34 (19.9\%) & $12.5[2.63 ; 299]$ & $17.9[2.25 ; 142.4]$ \\
\hline$>60$ & $375(53.9 \%)$ & $130(76.0 \%)$ & $20.0[4.42 ; 469]$ & $21.54[2.8 ; 165.6]$ \\
\hline \multicolumn{5}{|c|}{ MAXFIT (out of 3 samples) } \\
\hline$\leq 11$ & $508(73.0 \%)$ & $33(19.3 \%)$ & Ref. & Ref. \\
\hline$>11$ & $188(27.0 \%)$ & $138(80.7 \%)$ & $11.2[7.49 ; 17.3]$ & $2.31[0.99 ; 5.38]$ \\
\hline \multicolumn{5}{|c|}{ NSAMPLES $>4$} \\
\hline 0 & $441(63.4 \%)$ & $24(14.0 \%)$ & Ref. & Ref. \\
\hline 1 & $110(15.8 \%)$ & $18(10.5 \%)$ & $3.01[1.55 ; 5.74]$ & $2.98[1.54 ; 5.8]$ \\
\hline 2 & $71(10.2 \%)$ & $18(10.5 \%)$ & $4.65[2.37 ; 9.01]$ & $4.49[2.3 ; 8.8]$ \\
\hline 3 & $74(10.6 \%)$ & $111(64.9 \%)$ & $27.2[16.7 ; 46.0]$ & $28.1[16.8 ; 46.9]$ \\
\hline
\end{tabular}

MAXFIT: maximum f-Hb value; NSAMPLES $>4$ : Number of samples with FIT $>4 \mu \mathrm{g} \mathrm{Hb} / \mathrm{g}$ faeces

univariate analysis $(p<0.05)$ were introduced one by one into the seminal multivariate model and its C-Statistic and Brier score were recorded. Those variables that significantly improved the performance indexes (higher C-Statistic and lower Brier score) compared against the seminal values were chosen to be included in the final prognostic model (see Table 4). For each risk factor, we assigned a weight in the risk score using the respective odds ratio (OR) yielded by the logistic regression, where the maximum $\log$-OR received a score of 10 points. The risk score for an individual was the sum of their individual risk factors. Risk groups were classified according to the 'AddFor' algorithm, which allows for categorization of continuous variables in prediction models within a logistic regression model, in such a way that the best discriminative ability is obtained in terms of the highest C-Statistic [26]. This methodology allows for the selection of more than one cut point and better risk classification of patients.

\section{Statistical analysis}

The development and external validation of a multivariable prediction model study was designed according to TRIPOD statement [27]. A checklist indicating the pages where information for each item is reported can be found as a supplementary file (Additional file 4).

Statistical analysis was performed with R software [28]. Variables considered after variable selection in univariate analysis are listed in Tables 1 and 2. Other analysed variables such as family or personal history of CRC or colonic polyps were no informative. Missing-data were introduced as 'Unknown' and analysed as a new category of each variable; this was mainly observed for analytical variables related to iron deficiency since at inclusion many patients had received oral iron supplements.
A Bayesian logistic regression model accounting for age and NSAMPLES $>4$ depending on the levels of MAXFIT was fitted to each one of the variables considered, assuming a non-informative Cauchy prior for the model parameters [29]. Once the model was fitted, we derived the median OR and their 95\% credible interval from the subsequent distribution of the model parameters. The C-Statistic and the Brier score were used as the overall performance measures of the modelling [30], selecting the model with maximum $\mathrm{C}$-Statistic and minimum Brier score. Finally, the Hosmer-Lemeshow test was used to test the calibration of the model in the validation cohort $[24,30]$.

To assess the effect of using 3-sample FIT as compared to 1-sample FIT, we developed different models created with a FIT value randomly chosen from the 3 values of each patient. Also we compared the 3-sample FIT final model with a previously published 1-sample FIT test score (FAST score) [17]. For these comparisons we used the method proposed by DeLong et al. [31], as implemented by Robin et al. in pROC package [32].

\section{Results}

\section{Description of the derivation and validation cohorts}

Between April 2014 and February 2017, 1538 patients were included, 897 in the derivation (phase 1) and 641 in the validation (phase 2) cohorts (Fig. 1). Another 1595 patients either did not agree to participate or were not contacted with enough time before the colonoscopy. There were no differences in demographic characteristics and indications for colonoscopy between these and the included patients (data not shown). Forty-three patients $(2.8 \%)$ were excluded because of improper FIT collection. The indications for colonoscopy and the baseline characteristics 
Table 2 Univariate and age- and FIT-adjusted predictors of ACN in the derivation (Phase I) cohort: Crude and adjusted ORs, and CStatistic and Brier score of the adjusted model

\begin{tabular}{|c|c|c|c|c|c|}
\hline VARIABLE & $\begin{array}{l}\text { Control group } \\
\text { (Non-AA, non-CRC) }\end{array}$ & $\mathrm{AA}+\mathrm{CRC}$ & $\begin{array}{l}\text { OR (Crude) } \\
{[95 \% \mathrm{Cl}]}\end{array}$ & $\begin{array}{l}\text { OR (Adjusted) } \\
{[95 \% \mathrm{Cl}]}\end{array}$ & $\begin{array}{l}\text { C-Statistic/ Brier score } \\
\text { adjusted model }\end{array}$ \\
\hline & $N=696$ & $N=171$ & & & \\
\hline \multicolumn{6}{|l|}{ Gender } \\
\hline Man & $311(44.7 \%)$ & $103(60.2 \%)$ & Ref. & Ref. & \\
\hline Woman & $385(55.3 \%)$ & $68(39.8 \%)$ & $0.53[0.38 ; 0.75]$ & $0.81[0.53 ; 1.21]$ & $0.841 / 0.1158$ \\
\hline \multicolumn{6}{|c|}{ Body Mass Index $\left(\mathrm{Kg} / \mathrm{m}^{2}\right)$} \\
\hline$\leq 25$ & $246(35.3 \%)$ & $47(27.5 \%)$ & Ref. & Ref. & \\
\hline$>25$ & $450(64.7 \%)$ & $124(72.5 \%)$ & $1.44[1.01 ; 2.10]$ & $1.19[0.77 ; 1.85]$ & $0.841 / 0.1161$ \\
\hline \multicolumn{6}{|c|}{ Colonoscopy (5 years before) } \\
\hline No & $555(79.7 \%)$ & $153(89.5 \%)$ & Ref. & Ref. & \\
\hline Yes & $141(20.3 \%)$ & $18(10.5 \%)$ & $0.47[0.27 ; 0.77]$ & $0.35[0.21 ; 0.63]$ & $0.862 / 0.1031$ \\
\hline \multicolumn{6}{|l|}{ Smoking (History) } \\
\hline No & $359(51.6 \%)$ & $77(45.0 \%)$ & Ref. & Ref. & \\
\hline Yes (Ex/Current) & $337(48.4 \%)$ & $94(55.0 \%)$ & $1.30[0.93 ; 1.82]$ & $1.51[1.02 ; 2.29]$ & $0.859 / 0.1050$ \\
\hline \multicolumn{6}{|l|}{ Smoking (Years): } \\
\hline No & $359(51.6 \%)$ & $77(45.0 \%)$ & Ref. & Ref. & \\
\hline$\leq 42$ & $191(27.4 \%)$ & $25(14.6 \%)$ & $0.61[0.37 ; 0.98]$ & $1.17[0.6 ; 2.33]$ & \\
\hline$>42$ & $146(21.0 \%)$ & $69(40.4 \%)$ & $2.20[1.51 ; 3.21]$ & $1.65[0.99 ; 2.61]$ & $0.849 / 0.1086$ \\
\hline \multicolumn{6}{|c|}{$\begin{array}{l}\text { Drugs (NSAIDs or antiplatelet } \\
\text { or anticoagulants) }\end{array}$} \\
\hline No & $415(59.6 \%)$ & $98(57.3 \%)$ & Ref. & Ref. & \\
\hline Yes & $281(40.4 \%)$ & $73(42.7 \%)$ & $1.10[0.78 ; 1.54]$ & $0.79[0.52 ; 1.21]$ & $0.841 / 0.1153$ \\
\hline \multicolumn{6}{|l|}{ Anticoagulants } \\
\hline No & $673(96.7 \%)$ & $156(91.2 \%)$ & Ref. & Ref. & \\
\hline Yes & $23(3.30 \%)$ & $15(8.77 \%)$ & $2.82[1.40 ; 5.50]$ & $1.67[0.75 ; 3.80]$ & $0.842 / 0.1159$ \\
\hline \multicolumn{6}{|l|}{ NSAIDs } \\
\hline No & $525(75.4 \%)$ & $136(79.5 \%)$ & Ref. & Ref. & \\
\hline Yes & $171(24.6 \%)$ & $35(20.5 \%)$ & $0.79[0.52 ; 1.18]$ & $0.79[0.49 ; 1.29]$ & $0.846 / 0.1156$ \\
\hline \multicolumn{6}{|l|}{ Abdominal pain } \\
\hline No & $299(43.0 \%)$ & $97(56.7 \%)$ & Ref. & Ref. & \\
\hline Yes & $397(57.0 \%)$ & $74(43.3 \%)$ & $0.58[0.41 ; 0.81]$ & $0.77[0.52 ; 1.16]$ & $0.840 / 0.116$ \\
\hline \multicolumn{6}{|l|}{ Iron deficiency } \\
\hline No & $237(34.1 \%)$ & $56(32.7 \%)$ & Ref. & Ref. & \\
\hline Yes & $174(25.0 \%)$ & $55(32.2 \%)$ & $1.34[0.88 ; 2.04]$ & $0.92[0.55 ; 1.92]$ & \\
\hline Unknown & $285(40.9 \%)$ & $60(35.1 \%)$ & $0.89[0.59 ; 1.34]$ & $0.86[0.54 ; 1.37]$ & $0.840 / 0.116$ \\
\hline \multicolumn{6}{|c|}{ Iron deficiency anaemia } \\
\hline No & $371(53.3 \%)$ & $77(45.0 \%)$ & Ref. & Ref. & \\
\hline Yes & $166(23.9 \%)$ & $54(31.6 \%)$ & $1.57[1.05 ; 2.32]$ & $1.13[0.69 ; 1.84]$ & \\
\hline Unknown & $159(22.8 \%)$ & $40(23.4 \%)$ & $1.21[0.79 ; 1.85]$ & $1.14[0.69 ; 1.91]$ & $0.840 / 0.116$ \\
\hline \multicolumn{6}{|c|}{ Type change bowel habit } \\
\hline No & $261(37.5 \%)$ & $78(45.6 \%)$ & Ref. & Ref. & \\
\hline Diarrhoea & $226(32.5 \%)$ & $59(34.5 \%)$ & $0.87[0.59 ; 1.28]$ & $1.08[0.68 ; 1.71]$ & \\
\hline Constipation & $179(25.7 \%)$ & $31(18.1 \%)$ & $0.58[0.36 ; 0.91]$ & $0.71[0.42 ; 1.22]$ & \\
\hline Unknown & $30(4.31 \%)$ & $3(1.75 \%)$ & $0.35[0.08 ; 1.02]$ & $0.78[0.23 ; 2.74]$ & $0.840 / 0.1153$ \\
\hline
\end{tabular}


Table 2 Univariate and age- and FIT-adjusted predictors of ACN in the derivation (Phase I) cohort: Crude and adjusted ORs, and CStatistic and Brier score of the adjusted model (Continued)

\begin{tabular}{|c|c|c|c|c|c|}
\hline VARIABLE & $\begin{array}{l}\text { Control group } \\
\text { (Non-AA, non-CRC) }\end{array}$ & $\mathrm{AA}+\mathrm{CRC}$ & $\begin{array}{l}\text { OR (Crude) } \\
{[95 \% \mathrm{Cl}]}\end{array}$ & $\begin{array}{l}\text { OR (Adjusted) } \\
{[95 \% \mathrm{Cl}]}\end{array}$ & $\begin{array}{l}\text { C-Statistic/ Brier score } \\
\text { adjusted model }\end{array}$ \\
\hline \multicolumn{6}{|l|}{ Abdominal pain duration } \\
\hline No & $299(43.0 \%)$ & 97 (56.7\%) & Ref. & Ref. & \\
\hline Yes, 1-12 Days & $123(17.7 \%)$ & $26(15.2 \%)$ & $0.65[0.40 ; 1.05]$ & $0.65[0.37 ; 1.15]$ & \\
\hline Yes, $>12$ Days & $274(39.4 \%)$ & $48(28.1 \%)$ & $0.54[0.37 ; 0.79]$ & $0.86[0.54 ; 1.37]$ & $0.850 / 0.1157$ \\
\hline \multicolumn{6}{|l|}{ Rectal bleeding pattern } \\
\hline No & $342(49.1 \%)$ & $84(49.1 \%)$ & Ref. & Ref. & \\
\hline Yes, without specific pattern & $219(31.5 \%)$ & $43(25.1 \%)$ & $0.80[0.53 ; 1.20]$ & $0.59[0.36 ; 1.07]$ & \\
\hline Yes, with specific pattern & $135(19.4 \%)$ & $44(25.7 \%)$ & $1.44[0.97 ; 2.12]$ & $1.33[0.87 ; 2.01]$ & $0.849 / 0.1151$ \\
\hline \multicolumn{6}{|l|}{ Rectal bleeding duration (days) } \\
\hline No rectal bleeding & $342(49.1 \%)$ & $84(49.1 \%)$ & Ref. & Ref. & \\
\hline$\leq 30$ & $328(47.1 \%)$ & $74(43.3 \%)$ & $0.92[0.65 ; 1.30]$ & $0.63[0.41 ; 1.05]$ & \\
\hline$>30$ & $26(3.74 \%)$ & $13(7.60 \%)$ & $2.04[0.97 ; 4.10]$ & $0.86[0.37 ; 1.98]$ & $0.846 / 0.1150$ \\
\hline \multicolumn{6}{|l|}{ Haemoglobin (g/dL) } \\
\hline$\leq 11$ & $105(15.1 \%)$ & $43(25.1 \%)$ & Ref. & Ref. & \\
\hline$>11$ & $481(69.1 \%)$ & $112(65.5 \%)$ & $0.57[0.38 ; 0.86]$ & $1.02[0.61 ; 1.71]$ & \\
\hline Unknown & $110(15.8 \%)$ & $16(9.36 \%)$ & $0.36[0.18 ; 0.67]$ & $0.62[0.31 ; 1.31]$ & 0.847 / 0.1127 \\
\hline \multicolumn{6}{|l|}{ Ferritin (ng/mL) } \\
\hline$\leq 40$ & $176(25.3 \%)$ & $56(32.7 \%)$ & Ref. & Ref. & \\
\hline$>40$ & 225 (32.3\%) & 53 (31.0\%) & $0.74[0.48 ; 1.13]$ & $0.82[0.51 ; 1.34]$ & \\
\hline Unknown & $295(42.4 \%)$ & 62 (36.3\%) & $0.66[0.44 ; 0.99]$ & $0.85[0.52 ; 1.39]$ & 0.849 / 0.1106 \\
\hline \multicolumn{6}{|l|}{ CEA (ng/mL) } \\
\hline$\leq 12$ & $610(87.6 \%)$ & 135 (78.9\%) & Ref. & Ref. & \\
\hline$>12$ & $5(0.72 \%)$ & 11 (6.43\%) & $9.73[3.43 ; 32.1]$ & $2.91[0.88 ; 9.36]$ & \\
\hline Unknown & 81 (11.6\%) & 25 (14.6\%) & $1.40[0.85 ; 2.25]$ & $1.27[0.71 ; 2.27]$ & 0.849 / 0.1101 \\
\hline
\end{tabular}

of the patients included in each phase are shown in Additional file 6 and Additional file 7. One thousand fifty-eight patients met the NICE criteria for a fast-track colonoscopy and 237 did not (136 in phase 1 and 101 in phase 2).

We detected CRC in 67/867 (7.7\%) in study phase 1, and $49 / 628(7.8 \%)$ in phase 2 . No patient of the subgroup with negative FIT and who did not met the NICE criteria for a fast-track colonoscopy had a CRC. There were no significant differences in tumour localization and staging between the two phases (Additional file 5). Additionally, we found advanced adenomas in 203 patients, 104 (11.9\%) in phase 1 (5 with no NICE criteria and negative FIT) and 99 (15.7\%) in phase 2 (6 with no NICE criteria and negative FIT). Six adenomas in phase 1 had intramucosal carcinoma (Tis).

There were no significant differences in demographic and clinical variables between phase 1 and phase 2 included patients (Additional file 7). However, there were significant differences in the FIT variables (MAXFIT and NSAMPLES $>4$ ). In fact, all CRC patients in phase 1 had positive FIT with values above $11 \mu \mathrm{g} \mathrm{Hb} / \mathrm{g}$ faeces. In contrast, there were three CRC patients in phase 2 with negative FIT, and two patients with values $>4$ and $<$ $11 \mu \mathrm{g} \mathrm{Hb} / \mathrm{g}$ faeces. Overall, there were 6/116 (5\%) CRC patients with only 1 out of 3 faecal samples positive.

\section{Derivation of the predictive risk score}

Age and FIT variables were independently associated with the risk of $\mathrm{ACN}$, with ORs very much higher than other variables (Table 1). Univariate and age- and FIT-adjusted predictors of ACN in the derivation (Phase I) cohort are presented in Table 2. Only 'Colonoscopy up to 5 years before FIT', 'smoking history', and 'smoking years' retained overall statistical significance and improve C-Statistic and Brier score of the multivariate analyses. Both in the derivation and the validation cohorts, the C-Statistic with 'smoking history' was slightly better; thus we selected this simpler variable for the derived score. The derived predictive risk score is described in Table 3, which shows the multivariate predictors of ACN using the model fitted to the derivation (Phase I) cohort. The predictive score ranged from -4 to 24 points. The predictive performance 
Table 3 Multivariate predictors of ACN using the model fitted to the derivation (Phase I) cohort. The predictive score derived ranged from -4 to 24 points (Final model: C-Statistic $=0.865$; Brier Score $=0.10$; Hosmer-Lemeshow p-value $=0.86$ )

\begin{tabular}{|c|c|c|c|c|}
\hline Risk Factor & OR & Q 2.5 & Q 97.5 & Points \\
\hline Age $40-50$ years & 2.26 & 0.52 & 10.05 & 3 \\
\hline Age $50-60$ years & 7.58 & 2.02 & 28.56 & 8 \\
\hline Age $>60$ years & 11.88 & 3.27 & 43.13 & 10 \\
\hline Colonoscopy (in the previous 5 years) (Yes) & 0.36 & 0.2 & 0.65 & -4 \\
\hline Smoking (Yes) & 1.49 & 1.01 & 2.27 & 2 \\
\hline \multicolumn{5}{|l|}{ IF MAXFIT [> 4-11] } \\
\hline NSAMPLES $>4$ & 1.72 & 1.04 & 2.83 & $2 x+$ \\
\hline \multicolumn{5}{|l|}{ IF MAXFIT > 11} \\
\hline NSAMPLES $>4$ & 2.89 & 2.45 & 3.44 & $4 x+$ \\
\hline
\end{tabular}

MAXFIT: maximum f-Hb value; NSAMPLES > 4: Number of samples with FIT > $4 \mu \mathrm{g} \mathrm{Hb} / \mathrm{g}$ faeces. Discrete variable (0 to 3$)$. Points: Points assigned to each Risk Factor

†Note on $2 x / 4 x$ : factor to multiply NSAMPLES

How do we interpret the model? Ex: Suppose a 55-year-old man has not smoked or has done a prior colonoscopy and with values of FIT 4,6 and $10 \mu \mathrm{Hb} / \mathrm{g}$ faeces. This individual has a MAXFIT value of 10, and 2 samples with FIT $>4$ ( 2 positive samples); therefore its score will be 8 points by age +2 points per FIT (corresponding to the $\mathrm{OR}=1.72$ ) multiplied by 2 positive samples, giving 4 points. Total: 12 points. But if their FIT values were 4,8 , and $12 \mu \mathrm{g} H / \mathrm{g}$ faeces, the MAXFIT value of 12 and two positive samples, their score would be 8 points by age +4 points per FIT (corresponding to the OR $=2.89$ ) multiplied by 2 positive samples, giving 8 points. Total: 16 points

of the final risk score for $\mathrm{ACN}$ was excellent with a CStatistic of 0.865 (95\% CI, 0.83-0.89). Taking into account only CRC, the C-Statistic was 0.93 (95\% CI, 0.91-0.95).

\section{Effect of the number of positive samples on the predictive performance of the model}

We compared the model resulting from taking 1 random sample out of the 3 samples with the proposed final model for ACN which includes MAXFIT and NSAMPLES (Table 4). This was done 5 times. The C-Statistic from the five random samples were lower than that of the proposed final model, showing that the final model including the interaction between MAXFIT and NSAMPLES classified better a $2.2-3 \%$ of patients.

In addition, we compared our 3-sample FIT final model (COLONOFIT score) with the 1-sample FIT, age and sex test (FAST) score developed by Cubiella et al.

Table 4 Comparison of the model resulting from taking 1 random sample out of the 3 FIT samples with the proposed final model for ACN

\begin{tabular}{lll}
\hline MODEL & AUC & Cl 95\% (Bootstrap) \\
\hline With interaction $^{\dagger}$ & 0.865 & $0.833-0.894$ \\
${\text { RANDOM }-1^{\ddagger}}^{\text {RANDOM }-2_{2}}$ & 0.844 & $0.809-0.875$ \\
RANDOM - 3 & 0.835 & $0.800-0.897$ \\
RANDOM - 4 & 0.843 & $0.809-0.876$ \\
RANDOM - 5 & 0.842 & $0.808-0.875$ \\
\hline
\end{tabular}

${ }^{\dagger}$ Final model including MAXFIT and NSAMPLES

${ }^{\mp}$ RANDOM-N: Model created with a FIT value randomly chosen from the 3 values of each patient. This was repeated 5 times

MAXFIT: maximum $\mathrm{f}-\mathrm{Hb}$ value; NSAMPLES $>4$ : Number of samples with FIT > $4 \mu \mathrm{g} \mathrm{Hb} / \mathrm{g}$ faeces
[17] In study phase 1 , the C-Statistic for both CRC and ACN was significantly higher with COLONOFIT than FAST score $(\mathrm{CRC}, 0.93 \pm 0.009$ vs. $0.90 \pm 0.01 ; p=0.04$; and $\mathrm{ACN}, 0.86 \pm 0.02$ vs. $0.82 \pm 0.02 ; p=0.0007$ ) (Fig. 2). In addition, in study phase 2 , the C-Statistic for both $\mathrm{CRC}$ and $\mathrm{ACN}$ was also higher with COLONOFIT than FAST score (CRC, $0.86 \pm 0.025$ vs. $0.83 \pm 0.03 ; p=0.18$; and $\mathrm{ACN}, 0.79 \pm 0.02$ vs. $0.75 \pm 0.02 ; p=0.0034$ ). The differences between both scores were maintained after excluding the patients who did not met NICE criteria and had negative FIT (data not shown).

\section{Reliability of the model in the validation cohort}

As above mentioned, the risk-score was more accurate for $\mathrm{ACN}$ and $\mathrm{CRC}$ detection in the derivation than in the validation cohort. However, its performance remained good. The Hosmer-Lemeshow $p$-value was 0.86 , showing that the model was well calibrated.

Patients of the validation cohort were categorized into risk subgroups according the presence of $\mathrm{ACN}$ and the value of the final risk-score using the 'AddFor' algorithm (see methods) (Table 5). The probability (or prevalence) of ACN for a risk-score $>20$ points was $66 \%$, whereas for a risk-score $\leq 10$ points it was $10 \%$. If we take into account only CRCs, these probabilities were 32 and $1 \%$, respectively.

A risk-score $>10$ points allowed us to diagnose $96 \%$ of CRC and $72 \%$ of AA, with only needing to prioritize a $50 \%$ of colonoscopies (Table 6). No patient with a riskscore $<4$ points had CRC but in this case we need to prioritize $95 \%$ of colonoscopies. Higher cut-offs would prioritize fewer colonoscopies while increasing the percentage of CRC loss. 

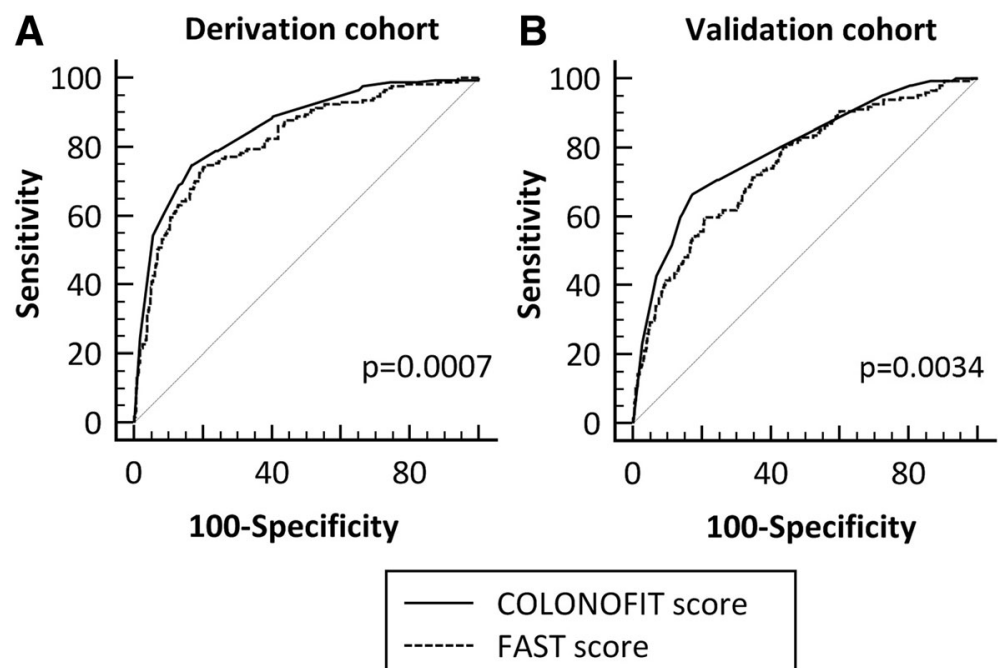

Fig. 2 Comparison of the C-Statistic of the present 3-sample FIT model (COLONOFIT score) with the 1-sample FIT, age and sex test (FAST) score ${ }^{17}$ for ACN diagnosis in both the derivation and validation phase

\section{Discussion}

A multivariable prediction modelling study to assess the pre-test-probability of ACN in symptomatic patients with indication of a fast-track colonoscopy was performed. This approach has been considered the most efficient method of capturing the effects of clinical judgement [33]. The derived and validated risk-score (COLONOFIT score) may be useful to prioritize colonoscopies in patients fulfilling criteria for a fast-track exploration. We saw as more relevant both the percentage of missed cases of CRC and the percentage of patients to prioritize than sensitivity and specificity to detect ACN. In fact, a risk-score $>10$ points, which would imply to prioritize $50 \%$ of eligible patients, allowed the overall diagnosis of $98 \%$ of CRC (2\% of missed CRC cases) and $77 \%$ of AA. It has been shown that decreasing the positivity threshold of FIT does not increase the detection rate of $\mathrm{ACN}$, and thus it is assumed that not all CRCs can be detected by using FIT [34, 35].

A 3-fecal sample FIT regime was used in order to increase the CRC detection rate, selecting the cut-off to consider a sample as positive on the basis of the DOR. This cut-off was lower than that used in the screening program of average-risk asymptomatic patients in our geographical area. The logistic regression analysis showed that in addition to age, a maximum $\mathrm{f}-\mathrm{Hb}$ level $>$ $11 \mu \mathrm{g} \mathrm{Hb} / \mathrm{g}$ faeces and the number of positive samples ( $>4 \mu \mathrm{g} \mathrm{Hb} / \mathrm{g}$ faeces) were the variables associated with the highest ORs to predict ACN. Noteworthy, having three positive samples was associated with ACN with the highest OR and C-Statistic. In contrast, no clinical symptom or clinical presentation was independently associated with the risk of ACN after adjusting for age and FIT variables. In fact, the low predictive value of clinical symptoms has been previously reported $[8,10,33]$. In addition to age and FIT variables, smoking increased while a previous colonoscopy (in the last 5 years) decreased the risk.

Some previous studies had suggested the use of FIT with other clinical variables or even only one-sample FIT plus age and sex (FAST score) as a predictive tool of CRC in symptomatic patients, showing more accuracy than symptom-based referral criteria [11, 17]. NICE referral criteria for suspected CRC have a $68.2 \%$ sensitivity and a $50.2 \%$ specificity for CRC detection and, actually, these criteria cannot rule out CRC [11]. In the present study, we showed that a COLONOTIF score $>10$ points has a sensitivity of $98 \%$ and a specificity of $53 \%$ to detect CRC, and in this sense the NPV was $99.7 \%$ and the LR0.03 . Although the specificity was not very high and a

Table 5 Probability of an individual classified based on its risk score (after applying the score derived from Phase 1 to the validation cohort, Phase 2). The cut-off points were selected using the 'AddFor' algorithm (see methods)

\begin{tabular}{|c|c|c|c|c|c|}
\hline Score & Prob (Control group)* & Prob (AA) & Prob (CRC) & $\begin{array}{l}\text { Prob (Control group)* } \\
(95 \% \mathrm{Cl})\end{array}$ & $\begin{array}{l}\text { Prob (AA+CRC) } \\
(95 \% \mathrm{Cl}) \\
\end{array}$ \\
\hline$>20$ & 0.34 & 0.34 & 0.32 & $0.34(0.28 ; 0.39)$ & $0.66(0.51 ; 0.76)$ \\
\hline $10-20$ & 0.76 & 0.16 & 0.07 & $0.76(0.65 ; 0.86)$ & $0.24(0.14 ; 0.31)$ \\
\hline$\leq 10$ & 0.90 & 0.09 & 0.01 & $0.90(0.84 ; 0.97)$ & $0.10(0.01 ; 0.16)$ \\
\hline
\end{tabular}

*Control group: Non-AA, non-CCR 
Table 6 Accuracy of a positive risk score (> 10 points) to diagnose both ACN and CCR in the validation cohort (Phase II) and in the derivation plus validation cohorts (Phase I + Phase II). Frequency of colonoscopy prioritization with the associated miss of either CRC or AA cases for a Score $>10$

\begin{tabular}{|c|c|c|c|}
\hline \multicolumn{4}{|l|}{ PHASE ॥ } \\
\hline & $\mathrm{ACN}$ & Control group (non-AA, non-CRC) & Total \\
\hline Score $>10$ & 118 (47 CCR) & 198 & 316 \\
\hline Score $\leq 10$ & 30 (2 CCR) & 282 & 312 \\
\hline \multirow[t]{2}{*}{ Total } & 148 & 480 & 628 \\
\hline & $\mathrm{ACN}$ & & CRC \\
\hline Sensitivity (\%) & $79(72-85.4)^{\dagger}$ & & $96(85-99)$ \\
\hline Specificity (\%) & $58(54.2-63)$ & & $52(48-56)$ \\
\hline PPV (\%) & $37(32-42.7)$ & & $14.4(11-19)$ \\
\hline NPV (\%) & $90(87-93.2)$ & & $99.3(97-99.9)$ \\
\hline Diagnostic OR & $5.6(3.6-8.7)$ & & $25.4(6.1-106)$ \\
\hline $\operatorname{LR}(+)$ & $1.93(1.7-2.2)$ & & $1.99(1.8-2.2)$ \\
\hline $\operatorname{LR}(-)$ & $0.34(0.25-0.48)$ & & $0.08(0.02-0.30)$ \\
\hline Prevalence (\%) & 23.6 & & 7.8 \\
\hline Score $\leq 10$ & $\mathrm{~N}$ & (\%) Loss & \\
\hline Missed cases of CRC & 2 & 4.1 & \\
\hline Missed cases of AA & 28 & 28.3 & \\
\hline Score $>10$ & N & (\%) Prioritization & \\
\hline Prioritization & 316 & 50.3 & \\
\hline \multicolumn{4}{|l|}{ PHASE I + PHASE ॥ } \\
\hline & $\mathrm{ACN}$ & $\begin{array}{l}\text { Control group } \\
\text { (non-AA, non-CRC }\end{array}$ & Total \\
\hline Score $>10$ & 270 (114 CRC) & 468 & 738 \\
\hline Score $\leq 10$ & 49 (2 CRC) & 708 & 757 \\
\hline \multirow[t]{2}{*}{ Total } & 319 & 1176 & 1495 \\
\hline & $\mathrm{ACN}$ & & CRC \\
\hline Sensitivity (\%) & $85(80.3-88)^{\dagger}$ & & $98(93-99.7)$ \\
\hline Specificity (\%) & $60(57.4-63)$ & & $53(51-56)$ \\
\hline PPV & $36(33.2-40)$ & & $15(13-18)$ \\
\hline NPV & 93.5 (91.5-95) & & $99.7(99-100)$ \\
\hline Diagnostic OR & $8.3(6-11.5)$ & & $65.2(16-265)$ \\
\hline $\operatorname{LR}(+)$ & $2.12(1.95-2.31)$ & & $2.10(1.98-2.24)$ \\
\hline $\operatorname{LR}(-)$ & $0.25(0.20-0.33)$ & & $0.03(0.008-0.13)$ \\
\hline Prevalence (\%) & 21.3 & & 7.76 \\
\hline Score $\leq 10$ & $\mathrm{~N}$ & (\%) Loss & \\
\hline Missed cases of CRC & 2 & 1.7 & \\
\hline Missed cases of AA & 47 & 23 & \\
\hline Score $>10$ & N & (\%) Prioritization & \\
\hline Prioritization & 738 & 49.3 & \\
\hline
\end{tabular}

${ }^{\dagger} 95 \% \mathrm{Cl}$

low specificity is associated with unnecessary referrals, it should be emphasized that a score $>10$ allowed to prioritize $50 \%$ of patients fulfilling NICE referral criteria, detecting $98 \%$ of CRCs, and avoiding $50 \%$ of fast-track colonoscopies. Furthermore, 70\% of patients with CRC had a score $>20$ points, which was associated with a specificity of $90 \%$. The present comparison shows that COLONOFIT score classified patients a 3-4\% better 
than the FAST score in both the derivation and validation cohorts. Further studies on a direct comparison of both scores are needed to assess if the 3-4\% gain in classification could be offset by lower adherence (by submitting 3 vs. 1 FIT).

Selecting patients attending primary care may prevent a selection bias of patients with higher prior probability of CRC [36]. The present study included mainly patients referred by primary care for a fast-track colonoscopy and, anyhow, the variable primary or secondary care referral was included in the analysis without showing significant association with ACN. Thus, the derived riskscore may guide primary care physicians in their referral decisions for a fast-track colonoscopy. COLONOFIT score allows risk-stratifying of patients in clinical practice to inform decision-making. Those patients with a score $>20$ ( $15 \%$ of the patients in the validation cohort) had a risk of ACN of $66 \%$ (32\% CRC, 34\% AA) and should be sent for a 2WW colonoscopy. In contrast, those with a score $\leq 10$ (50\% of patients in the validation cohort) had a risk of $\mathrm{ACN}$ of $10 \%$ (1\% CRC, 9\% AA), and should be referred to either gastroenterology or other appropriate clinic in secondary care or a colonoscopy in the conventional slower referral route.

After developing the prediction model in the derivation cohort, its performance was evaluated in a different cohort (validation cohort), collected using the same protocol and outcome definitions and measurements, but sampled from a later period. Such external validation implies that for each individual in the new data set, outcome predictions were made using the derived predictive score $[37,38]$. The performance of a predictive model is typically worse when evaluated on samples independent of the sample used to develop the model. In fact, in phase 1 of the study all CRC patients and $82 \%$ of AA had a score $>10$; however, the performance characteristics in the validation cohort remained good.

Prevalence of CRC in symptomatic patients of the present study was near $8 \%$, and that of $\mathrm{ACN}$ around $24 \%$, which are figures much higher than those observed in the CRC screening populations (typically, ACN has a prevalence $<10 \%$ in that setting), and similar to other previous studies $[11,17]$. This reflects the need for a different diagnostic approach in the two settings, and in this sense, lower cut-offs of FIT have been suggested for symptomatic patients [7]. Results of the present study suggest that using 3-sample FIT (on three different days) is an additional diagnostic strategy that increases the prior probability of ACN. The 3-sampling strategy for FOBT was traditionally used for guaiac-based tests, and was abandoned when introducing the more sensitive FITs, and a meta-analysis showed that in average-risk asymptomatic patients increasing the number of FIT samples did not affect the pooled performance characteristics of FITs for CRC [18]. It was concluded that a 1-sample FIT regimen for CRC detection might ultimately be desirable, given the importance of optimizing overall adherence in repeated rounds of biennial testing for programmatic screening. However, several studies have directly evaluated the effect of FIT sample number on the diagnostic accuracy of FITs in averagerisk asymptomatic participants [19-21], and in symptomatic patients [22, 23], suggesting that using either 2 or 3 tests provided the best discrimination for CRC. Therefore, these data and the results of the present study suggest that using 3-sample FIT may increase the detection rate of $\mathrm{ACN}$ in patients with risk symptoms to an acceptable number needed to scope.

Not all studies on statistical risk models to predict CRC in people with symptoms included AA in addition to CRC. However, it is widely accepted that CRC arises from the adenoma-carcinoma sequence and so identification of patients with high-risk adenoma has the potential to reduce future incidence of invasive CRC and prevent mortality. A systematic review performed in 2016 included only two models assessing CRC plus AA [13], both of which reported only limited performance data and which have not been externally validated $[39,40]$. We think that the priority of the model should be to identify both prevalent CRC and the patients at high risk of developing $\mathrm{CRC}$ in the future, and in this sense, the COLONOFIT score prioritizes symptomatic patients to detect both CRC and AA.

This study has specific strengths that deserve to be highlighted. All included patients had a colonoscopy (even those with negative FIT); the best cut-off point of FIT was selected on the basis of the results, using the DOR value which maximizes the probability of $\mathrm{ACN}$; a 3-sample FIT regime was evaluated to assess whether the number of positive samples influenced the probability of ACN; a face-to-face structured and detailed survey was prospectively performed by a trained person; the external validation of the score was performed in a new cohort selected later in time; the derived risk score is ease of use, and all its components are readily available to general practitioners. The study has also some limitations. First, not all included patients were primary care referrals, but as noted earlier, there was no significant association with the referral origin, and all physicians used the same criteria to refer a patient for a fast-track colonoscopy that were reviewed by the case manager before inclusion. Second, the included patients fulfilled the criteria for a fast-track colonoscopy; thus the use of the predictive score cannot be generalized to patients without these criteria without further studies. Finally, there were missing data about iron status (patients were receiving iron supplements) without statistical significance comparing the two study phases, which could have precluded finding a significant association. 


\section{Conclusion}

A risk-scoring system was derived and validated to prioritize fast-track colonoscopies, which was shown to be efficient, simple, and robust. Further external validation studies are needed to warrant the widespread recommendation of the model in clinical practice.

\section{Additional files}

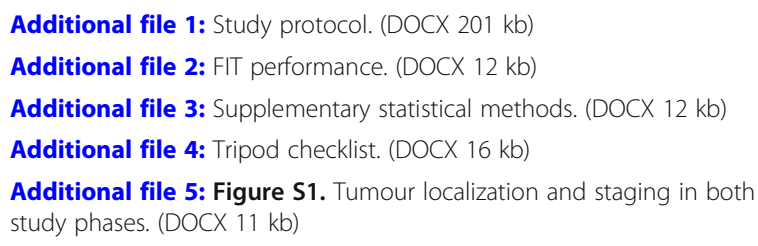

Additional file 6: Table S1 Indication for colonoscopy in both study phases. (DOCX $12 \mathrm{~kb}$ )

Additional file 7: Table S2 Description of patients included in study phase 1 and 2. (DOCX $22 \mathrm{~kb}$ )

Additional file 8: Dataset supporting the conclusions of this article. (ZIP $1179 \mathrm{~kb}$ )

\section{Abbreviations}

2WW: 2-week wait; AA: Advanced adenoma; ACN: Advanced colonic neoplasia; CRC: Colorectal cancer; f-Hb: Faecal haemoglobin; FIT: Faecal immunological occult haemoglobin test; MAXFIT: Maximum $\mathrm{f}-\mathrm{Hb}$ value

\section{Acknowledgements}

The study results were partially presented in the United European Gastroenterology congress held in Vienna (October 2018), and published as an abstract in UEG Journal.

The 'Centro de Investigación Biomédica en Red de Enfermedades Hepáticas y Digestivas (CIBERehd)' is an initiative of the Instituto de Salud Carlos III, Ministry of Health, Spain. This institution had no role in the study design, acquisition, and analysis, or interpretation of the data and report writing. Investigators from the COLONOFIT project who also participated in the study: Hospital Universitari Mútua Terrassa: Victoria Gonzalo (Department of Gastroenterology), Carme Ferrer (Department of Pathology); Hospital Parc Taulí de Sabadell: Alex Casalots (Department of Pathology); Consorci Sanitari de Terrassa: Ismael Jurado (Department of Pathology); CATLAB, Eva Guillén.

\section{Authors' contributions}

Guarantor of the article: FF-B. Specific author contributions: FF-B, RCl, JB, JR, $A A$, and RC designed the study; FF-B, JB, RC, SG, EM-B, MP1, MP2, PP, and RC contributed to data collection; $A A$ performed all the laboratory studies; $\mathrm{RCl}$ and JCO performed all statistical analysis; JR and XS checked the correct completion of the database; FF-B, study supervision; FF-B and $\mathrm{RCl}$ wrote the first draft of the manuscript. All authors approved the final version of the article, including the authorship list.

\section{Funding}

This study was supported by a grant from the Fundació La Marató de TV3 (785/U/2013), Catalunya, Spain. This sponsor had no role in the study design, nor in the acquisition, analysis, or interpretation of the data, or the writing of the report.

\section{Availability of data and materials}

Data supporting the findings of this paper are available as Supplementary information (Additional file 8).

\section{Ethics approval and consent to participate}

Patients were informed through a patient information sheet outlining the details of the project. Completion of the patient consultation questionnaire was entirely on a voluntary basis in compliance with the ethics committees of the participating hospitals. The study project was approved by the Ethical and Research Committee of the Hospital Universitari Mutua Terrassa (Terrassa, Barcelona, Spain) (20-March-2013; acta 03/2013).

\section{Consent for publication}

Not applicable.

\section{Competing interests}

None of the authors of this manuscript has any financial arrangement with any company whose product figures in the manuscript or that makes a competing product.

CATLAB is the 'Laboratory of Clinical Analyses' of the participating hospitals, and it is not a commercial company.

\section{Author details}

'Department of Gastroenterology, Hospital Universitari Mutua Terrassa, Plaza Dr Robert 5, 08221 Terrassa, Barcelona, Spain. ${ }^{2}$ Centro de Investigación Biomédica en Red de enfermedades hepáticas y digestivas (CIBERehd), Instituto Salud Carlos III, Madrid, Spain. ${ }^{3}$ Pla Director d'Oncologia, IDIBELL, L'Hospitalet de Llobregat, Barcelona, Spain. ${ }^{4}$ Department of Gastroenterology, Consorci Sanitari de Terrassa, Terrassa, Barcelona, Spain. ${ }^{5}$ CATLAB, Viladecavalls, Barcelona, Spain. ${ }^{6}$ Department of Gastroenterology, Hospital Parc Taulí, Sabadell, Barcelona, Spain.

Received: 13 May 2019 Accepted: 11 July 2019

Published online: 25 July 2019

\section{References}

1. Arnold M, Sierra MS, Laversanne M, et al. Global patterns and trends in colorectal cancer incidence and mortality. Gut. 2017;66:683-91.

2. Hamilton W, Round A, Sharp D, et al. Clinical features of colorectal cancer before diagnosis: a population-based case-control study. Br J Cancer. 2005; 93:399-405.

3. Hamilton W, Sharp D. Diagnosis of colorectal cancer in primary care: the evidence base for guidelines. Fam Pract. 2004;21:99-106.

4. Lawrenson R, Logie J, Marks C. Risk of colorectal cancer in general practice patients presenting with rectal bleeding, change in bowel habit or anaemia. Eur J Cancer Care (Engl). 2006;15:267-71.

5. Jones R, Latinovic R, Charlton J, et al. Alarm symptoms in early diagnosis of cancer in primary care: cohort study using general practice research database. BMJ. 2007;334:1040.

6. Thorne K, Hutchings HA, Elwyn G. The effects of the two-week rule on NHS colorectal cancer diagnostic services: a systematic literature review. BMC Health Serv Res. 2006;6:43.

7. NICE guideline [NG12]. Suspected cancer: recognition and referral. Last updated: July 2017. https://www.nice.org.uk/guidance/ng12/chapter/1Recommendations-organised-by-site-of-cancer\#lower-gastrointestinal-tractcancers

8. Jellema $P$, van der Windt DA, Bruinvels DJ, et al. Value of symptoms and additional diagnostic tests for colorectal cancer in primary care: systematic review and meta-analysis. BMJ. 2010;340:C1269.

9. Cubiella J, Salve M, Díaz-Ondina M, et al. Diagnostic accuracy of the faecal immunochemical test for colorectal cancer in symptomatic patients: comparison with NICE and SIGN referral criteria. Color Dis. 2014;16:0273-82.

10. Astin M, Griffin T, Neal RD, et al. The diagnostic value of symptoms for colorectal cancer in primary care: a systematic review. Br J Gen Pract. 2011; 61:e231-43.

11. Cubiella J, Vega $P$, Salve M, et al. COLONPREDICT study investigators Development and external validation of a faecal immunochemical testbased prediction model for colorectal cancer detection in symptomatic patients. BMC Med. 2016;14:128.

12. Zafar A, Mak T, Chapman MAS. The 2-week wait referral system does not improve 5-year colorectal cancer survival. Colorectal Dis. 2011;14:el77-80.

13. Williams TG, Cubiella J, Griffin SJ, et al. Risk prediction models for colorectal cancer in people with symptoms: a systematic review. BMC Gastroenterol. 2016;16:63.

14. Hodder RJ, Ballal M, Selvachandran SN, et al. Pitfalls in the construction of cancer guidelines demonstrated by the analyses of colorectal referrals. Ann R Coll Surg Engl. 2005;87:419-26.

15. Rai S, Ballal M, Thomas WM, et al. Assessment of a patient consultation questionnaire-based scoring system for stratification of outpatient risk of colorectal cancer. Br J Surg. 2008;95:369-74. 
16. Ballal MS, Selvachandran SN, Maw A. Use of a patient consultation questionnaire and weighted numerical scoring system for the prediction of colorectal cancer and other colorectal pathology in symptomatic patients: a prospective cohort validation study of a welsh population. Color Dis. 2010; 12:407-14.

17. Cubiella J, Digby J, Rodríguez-Alonso L, et al. COLONPREDICT study investigators. The fecal hemoglobin concentration, age and sex test score: development and external validation of a simple prediction tool for colorectal cancer detection in symptomatic patients. Int J Cancer. 2017;140: 2201-11.

18. Lee JK, Liles EG, Bent S, et al. Accuracy of fecal immunochemical tests for colorectal cancer: systematic review and meta-analysis. Ann Intern Med. 2014;160:171.

19. Nakama H, Yamamoto M, Kamijo N, et al. Colonoscopic evaluation of immunochemical fecal occult blood test for detection of colorectal neoplasia. Hepatogastroenterology. 1999;46:228-31.

20. Park DI, Ryu S, Kim YH, et al. Comparison of guaiac-based and quantitative immunochemical fecal occult blood testing in a population at average risk undergoing colorectal cancer screening. Am J Gastroenterol. 2010;105: 2017-25.

21. Raginel T, Puvinel J, Ferrand O, et al. A population-based comparison of immunochemical fecal occult blood tests for colorectal cancer screening. Gastroenterology. 2013;144:918-25.

22. Wu D, Luo HQ, Zhou WX, et al. The performance of three-sample qualitative immunochemical fecal test to detect colorectal adenoma and cancer in gastrointestinal outpatients: an observational study. PLoS One. 2014;9: e106648.

23. Högberg C, Söderström L, Lilja M. Faecal immunochemical tests for the diagnosis of symptomatic colorectal cancer in primary care: the benefit of more than one sample. Scand J Prim Health Care. 2017;35:369-72.

24. Hosmer DW, Lemeshow S. Applied logistic regression. New York: Wiley; 1989

25. Fernández-Bañares $F$, Alsius $A$, Campo $R$, et al Value of the immunochemical faecal test for human haemoglobin in the prioritization of diagnostic colonoscopy] (abstract). Gastroenterol Hepatol 2013; 36:172.

26. Barrio I, Arostegui I, Rodríguez-Álvarez MX, et al. A new approach to categorising continuous variables in prediction models: proposal and validation. Stat Methods Med Res. 2017;26:2586-602.

27. Collins GS, Reitsma JB, Altman DG, et al. Transparent reporting of a multivariable prediction model for individual prognosis or diagnosis (TRIPOD): the TRIPOD statement. Ann Intern Med. 2015;162:55-63.

28. R Core Team. R: A language and environment for statistical computing. $R$ Foundation for Statistical Computing, Vienna, Austria, 2015. URL https:// www.R-project.org

29. Gelman A, Jakulin A, Pittau MG, et al. A weakly informative default prior distribution for logistic and other regression models. Ann Appl Stat. 2008;2: 1360-83.

30. Harrell FE Jr. Regression modelling strategies: with applications to linear models, logistic regression, and survival analysis. Switzerland: Springer; 2001.

31. DeLong E, DeLong DM, Clarke-Pearson DL. Comparing the areas under two or more correlated receiver operating characteristic curves: a nonparametric approach. Biometrics. 1988;44:837-45.

32. Robin X, Turck N, Hainard A, et al. pROC: an open-source package for R and S+ to analyze and compare ROC curves. BMC Bioinformatics. 2011;12:77.

33. Westwood M, Corro Ramos I, Lang S, et al. Faecal immunochemical tests to triage patients with lower abdominal symptoms for suspected colorectal cancer referrals in primary care: a systematic review and cost-effectiveness analysis. Health Technol Assess. 2017;21:1-234

34. Ibañez-Sanz G, Garcia M, Milà N, et al. False-negative rate cannot be reduced by lowering the haemoglobin concentration cut-off in colorectal cancer screening using faecal immunochemical test. Eur J Cancer Prev. 2017:26:365-7.

35. Digby J, Fraser CG, Carey FA, et al. Interval cancers using a quantitative faecal immunochemical test (FIT) for haemoglobin when colonoscopy capacity is limited. J Med Screen. 2016;23:130-4

36. Rubin G, Hamilton W. Alarm features of colorectal cancer. Gut. 2009;58: 1026-7.

37. Moons KG, Kengne AP, Grobbee DE, et al. Risk prediction models: II. External validation, model updating, and impact assessment. Heart. 2012;98:691-8.

38. Altman DG, Vergouwe $Y$, Royston $P$, et al. Prognosis and prognostic research: validating a prognostic model. BMJ. 2009:338:b605.
39. Lam DT, Choy CL, Lam SC, et al. Age and symptoms as a triage method for per-rectal bleeding. Ann Coll Surg Hong Kong. 2002;6:77-82

40. Hurst NG, Stocken DD, Wilson S, et al. Elevated serum matrix metalloproteinase 9 (MMP-9) concentration predicts the presence of colorectal neoplasia in symptomatic patients. Br J Cancer. 2007;97:971-7.

\section{Publisher's Note}

Springer Nature remains neutral with regard to jurisdictional claims in published maps and institutional affiliations.

\section{Ready to submit your research? Choose BMC and benefit from:}

- fast, convenient online submission

- thorough peer review by experienced researchers in your field

- rapid publication on acceptance

- support for research data, including large and complex data types

- gold Open Access which fosters wider collaboration and increased citations

- maximum visibility for your research: over $100 \mathrm{M}$ website views per year

At $\mathrm{BMC}$, research is always in progress.

Learn more biomedcentral.com/submissions 